\title{
Experiência do Projeto "Fábrica de Software" em um Curso de Engenharia de Software
}

\author{
Alexandro Sousa dos Santos, Matheus Neves, Yuri Rodrigues, \\ Nisio H. de Oliveira, Daniel Kuhn, Gustavo Santos, Rodolfo A. Silva
}

\author{
Universidade Tecnológica Federal do Paraná (UTFPR), Campus Dois Vizinhos \\ Coordenação do Curso de Engenharia de Software (COENS-DV), Dois Vizinhos, Brasil
}

\begin{abstract}
Fábrica de Software", or Software Factory, was conducted as a teaching project, with the goal of uniting formative objectives from the Bachelor of Software Engineering course with development of real-world software, in a process that simulates a software industry. During five months, professors and five students from different semesters participated in the project. This paper reports observed results and challenges from this experience. The opportunity of learning from real-world problems and the overload of activities from remote classes were the key factors that participants identified in this project.
\end{abstract}

Resumo. A "Fábrica de Software" foi realizada como um projeto de ensino, com o objetivo de aproximar os objetivos formadores esperados do curso de Bacharelado em Engenharia de Software com o desenvolvimento de softwares reais, em um processo que simula uma indústria de software. O projeto teve duração de cinco meses, contou com o apoio de docentes do curso e a participação ativa de cinco discentes de diferentes períodos. O presente artigo relata o desenvolvimento desse projeto, resultados e desafios observados. Destacaram-se o contato e aprendizado com problemas reais, e a sobrecarga com atividades decorrentes do ensino remoto.

\section{Introdução}

O curso de Bacharelado em Engenharia de Software (BES) tem como objetivo geral formar profissionais aptos a trabalhar sobre um artefato de software, em alguns papéis como os de desenvolvedor, testador, analista ou gerente de projetos. Por meio das Diretrizes Curriculares Nacionais (DCNs) para os cursos de graduação na área de Computação [Conselho Nacional de Educação 2020], destacam-se três pontos esperados dos egressos do curso: (i) que sejam capazes de criar soluções, individualmente ou em equipe, para problemas complexos caracterizados por relações entre domínios de conhecimento e de aplicação; (ii) que sejam capazes de agir de forma reflexiva na construção de software, compreendendo o seu impacto direto ou indireto sobre as pessoas e a sociedade; e (iii) que entendam o contexto social no qual a construção de Software é praticada, bem como os efeitos dos projetos de software na sociedade.

No entanto, no decorrer do curso, alguns desafios são apresentados aos docentes e discentes. Devido à falta de experiência em ambientes reais de desenvolvimento de software, perguntas como "Onde vou usar isso?" e "Isso é realmente importante?" são recorrentes durante as aulas. Parcialmente, esses desafios são tratados em disciplinas de integração e estágio obrigatório, nas quais os discentes implementam soluções em 
software, unindo o conteúdo das disciplinas aprendidas até o momento. Entretanto, por mais que as disciplinas sejam conduzidas corretamente, elas ainda possuem limitações, seja na carga horária da disciplina (incluindo avaliações, apresentações, etc.), seja na complexidade das atividades destinadas ao discente dentro da carga horária proposta.

O projeto "Fábrica de Software" surgiu de um conjunto de necessidades do curso de Engenharia de Software, a exemplo (i) da importância da integração de disciplinas do curso para elaboração de uma solução em software, (ii) de demandas da instituição de ensino em projetos que beneficiassem o câmpus e a sociedade civil, e (iii) da aplicação de um projeto de ensino que integrasse discentes de diversos períodos. O projeto foi conduzido de forma remota, em estilo home-office, por cinco meses e contou com a participação ativa de cinco discentes do curso. O presente artigo apresenta os resultados desse projeto.

\section{Trabalhos Relacionados}

Com o intuito de fornecer aos alunos experiências do mercado de trabalho durante a formação universitária, cursos de Engenharia de Software no Brasil e no exterior vêm desenvolvendo projetos integralizadores a exemplo da Fábrica de Software.

Em 2010, o Instituto Federal de Educação Ciência e Tecnologia do Rio Grande do Sul - Câmpus Porto Alegre (IFRS-POA) desenvolveu um projeto de extensão, que consistiu na proposta de soluções e suporte a projetos do instituto e na promoção de ações de extensão como palestras e cursos [Borges et al. 2012]. Uma ação do projeto, denominada residência em Desenvolvimento de Software, faz uma alusão à residência médica na qual o aluno vive uma experiência profissional em um ambiente próximo do encontrado no mercado de trabalho. Os beneficiários, ou "clientes", do projeto consistiam nos próprios professores e técnicos administrativos, que geraram demandas em sistemas de suporte ao auxílio estudantil e controle de estágios da instituição. Dentre os benefícios do programa, destacam-se o compartilhamento de experiências dos próprios alunos em palestras e cursos, a oportunidade do aluno realizar o estágio ou trabalho de conclusão de curso na "Fábrica" e a redução de evasão nos cursos.

O projeto de "Fábrica de Software" do Instituto Federal de Educação, Ciência e Tecnologia Catarinense - Câmpus Araquari iniciou em 2013 e continua até hoje [Mota et al. 2014]. A participação dos alunos do curso de Bacharelado em Sistemas de Informação é condição necessária para que estes atinjam seu objetivo formativo. No projeto, os alunos realizam atividades de desenvolvimento de soluções, prestação de serviços de consultoria, desenvolvimento de cursos nas diversas áreas da computação e serviços de certificação em atividades que envolvam as áreas da computação. O projeto também prevê a participação de um aluno bolsista que acompanha todos os projetos ativos, no papel de "gerente". A experiência da "Fábrica" proporcionou um ambiente para vivência de projetos com e sem a aplicação de conceitos da Engenharia de Software e da Programação, tais como código limpo (clean code [Martin 2009]). A consequência da não aplicação desses conceitos serviu de objeto de estudo nas disciplinas do curso. Os autores também destacam que a construção de uma área física na qual os alunos pudessem desenvolver suas atividades foi de suma importância para que a proposta de "Fábrica" tivesse sucesso.

A Pontifícia Universidade Católica do Rio Grande do Sul (PUCRS) possui desde 2015 um projeto chamado Agência Experimental de Engenharia de Software (AGES) que permite aos alunos desenvolverem projetos de software com clientes reais. Por meio 
desse projeto, os alunos podem atuar em diversos papeis no contexto do ciclo de vida do software, como desenvolvedor, testador, analista, arquiteto de software e gerente de projetos, permitindo aos alunos desenvolverem e aprimorarem as habilidades requeridas a um profissional da área [Dutra et al. 2017, Chanin et al. 2019]. Os autores trazem o resultado de um survey com 52 participantes, cujos resultados revelaram a contribuição da AGES para o conhecimento da tecnologia, para gestão de projeto e trabalho em equipe.

\section{Projeto "Fábrica de Software"}

A "Fábrica de Software" foi realizada inicialmente como um projeto de Ensino, iniciado em Março de 2021 com apoio da UTFPR por meio de edital de apoio. A equipe inicial do projeto foi formada por três docentes, que estabeleceram os primeiros contatos com setores do câmpus, a fim de coletar demandas que poderiam ser solucionadas via software.

\subsection{Demanda Inicial: Controle de Entradas}

Junto ao Departamento de Serviços Gerais da Universidade, foi identificada uma demanda do controle de entrada e saída de discentes fora do horário de expediente do câmpus como, por exemplo, durante finais de semana e feriados. Anteriormente, a liberação de um discente era solicitada pelo docente responsável pelo mesmo. A liberação era aprovada ou cancelada pelo servidor responsável pelo Departamento de Serviços Gerais, e controlada via planilha eletrônica compartilhada.

No momento da chegada do discente ao câmpus, o vigilante deveria ser responsável por acessar essa planilha eletrônica, de modo a conferir se o discente estaria liberado a entrar no câmpus, e registrar em papel a entrada e saída desse discente, além de outras informações como placa do veículo, número de matrícula do discente e local de destino (laboratório, auditório, etc.). O controle de entradas e saídas (em papel, e preenchidas pelo vigilante) eram passadas ao servidor do Departamento ao final do expediente do vigilante. Esses documentos seriam posteriormente consultadas pelo servidor, sob demanda, gerando um processo oneroso de pesquisa em papel, além da carga desnecessária de material não digitalizado.

\subsection{Desenvolvimento do Sistema}

Durante as primeiras reuniões entre a equipe de docentes e o servidor responsável pelo Departamento de Serviços Gerais, foi proposto um sistema Web para o controle de entradas de discentes no câmpus. Com o auxílio de uma docente colaboradora do projeto, foram elencadas as funcionalidades e Estórias do Usuário para o sistema, estes primeiros apresentados na Tabela 1.

Tabela 1. Funcionalidades do sistema desenvolvido na Fábrica de Software.

\begin{tabular}{c|l}
\hline Func. & Descrição \\
\hline F1 & Realizar cadastro no sistema. \\
\hline F2 & Acessar o sistema. \\
\hline F3 & Cadastrar a liberação de um aluno. \\
\hline F4 & Editar uma liberação existente. \\
\hline F5 & Aprovar liberação de um aluno. \\
\hline F6 & Registrar visita (entrada ou saída) de um aluno. \\
\hline F7 & Gerar relatórios de entradas e saídas. \\
\hline
\end{tabular}


Por meio de edital de apoio, o projeto da "Fábrica" contou com duas bolsas estudantis para a condução das atividades. Nesse sentido, foi realizada uma seleção de discentes do curso de BES, a partir do segundo período, para preenchimento dessas bolsas e captação de possíveis discentes candidatos. Ao final da seleção e durante a condução do projeto, a equipe de desenvolvimento contou com seis integrantes, sendo um docente que coordenou o projeto e cinco discentes.

Em reuniões com a equipe, o processo de desenvolvimento foi inspirado na metodologia ágil Scrum [Schwaber and Sutherland 2017]. O sistema foi desenvolvido de forma incremental e, a cada novo ciclo de desenvolvimento (sprint), novas funcionalidades eram adicionadas. Os integrantes da equipe de desenvolvimento, assim como suas funções dentro da metodologia Scrum, são descritas na Tabela 2. Os discentes bolsistas eram líderes de suas equipes (front-end e back-end), portanto era esperado que os bolsistas também gerenciassem suas equipes para entrega dos incrementos no final das sprints.

Tabela 2. Equipe de execução do projeto "Fábrica de Software"

\begin{tabular}{c|c|l}
\hline Apelido. & Semestre & Função \\
\hline Docente 1 & - & Product Owner \\
\hline Discente 1 & $3^{\mathbf{o}}$ & Desenvolvedor full stack e Gerente de BD \\
\hline Discente 2 & $4^{\mathbf{o}}$ & Desenvolvedor back-end \\
\hline Discente 3 & $6^{\mathbf{o}}$ & Desenvolvedor back-end \\
\hline Discente 4 & $3^{\mathbf{o}}$ & Desenvolvedor front-end \\
\hline Discente 5 & $8^{\circ}$ & Designer e Scrum Master \\
\hline
\end{tabular}

O projeto foi dividido em 12 sprints com duração de duas semanas cada, de Março ao final de Agosto de 2021. Todos os discentes já trabalhavam em horário comercial e, à noite, acompanhavam disciplinas da graduação em atividades remotas; portanto, não houve necessidade de reuniões diárias (dailies do Scrum), sendo estas mantidas apenas nas segundas e sextas. Durante as reuniões, os discentes informavam o progresso das atividades em andamento, e estimavam que atividades seriam realizadas até a próxima reunião. As reuniões foram realizadas utilizando a plataforma Discord ${ }^{1}$, por meio de salas de áudio-conferência. O aplicativo de gerenciamento de projeto Trello ${ }^{2}$ foi utilizado para auxiliar o controle do andamento das atividades. Todo o trabalho foi realizado remotamente, dadas as limitações impostas pela pandemia COVID-19.

\section{Resultados}

Em reuniões iniciais com a equipe de desenvolvimento, foi definido que o sistema proposto seria Web responsivo, ou seja, os elementos gráficos seriam visíveis e dispostos para usuários de navegadores Web quanto para usuários de telefone móvel. O projeto foi desenvolvido nas linguagens de programação JavaScript, TypeScript, CSS (Cascading Style Sheets), e as bibliotecas Node.JS e React. A seguir, são apresentadas algumas funcionalidades do sistema desenvolvido, devido a limitações de espaço.

A Figura 1 apresenta o processo de registro da entrada de um aluno no câmpus (F6). O vigilante consulta quais alunos estão liberados naquele dia (Figura 1.a). Ao selecionar uma liberação, o vigilante poderá consultar mais informações, como o registro

\footnotetext{
${ }^{1}$ https://discord.com/

${ }^{2}$ https://trello.com/pt-BR
} 
acadêmico do aluno e o professor responsável pelo mesmo (Figura 1.b). Caso o aluno esteja liberado, o vigilante poderá registrar a entrada do aluno (Figura 1.c). Algumas informações são carregadas automaticamente, a exemplo da data e hora no momento do registro e o nome do vigilante. Outras informações poderão ser fornecidas, tais como a placa do veículo, e outras informações pertinentes ao registro (e.g., o aluno não levou documento de identificação no momento da entrada).

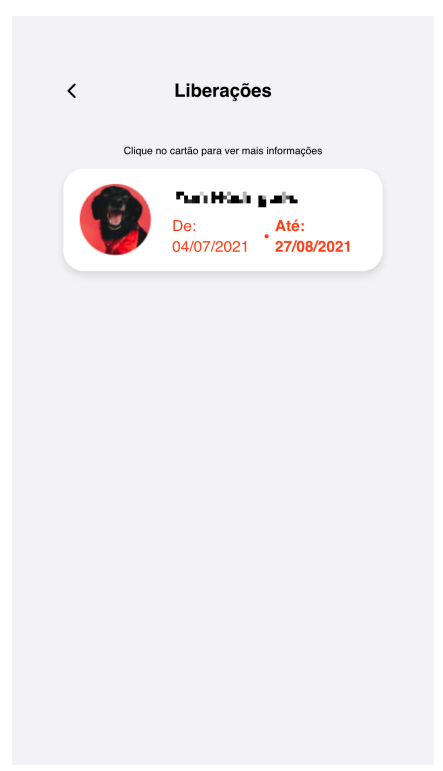

(a) Liberações no dia

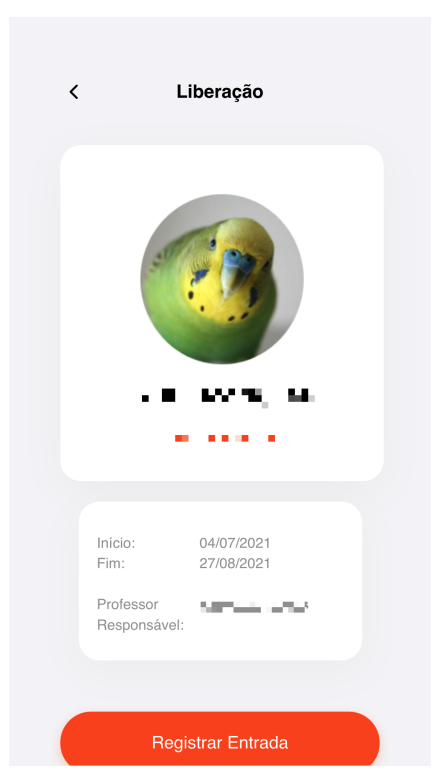

(b) Informações do aluno

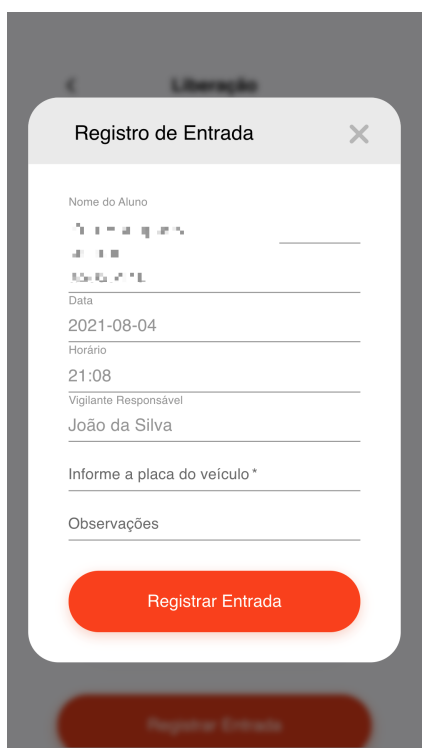

(c) Cadastro de entrada

Figura 1. Telas de registro de entrada (F6).

O processo finaliza na Figura 2, quando o aluno está deixando o câmpus. A partir da página inicial do vigilante (Figura 2.a), este poderá acessar as visitas pendentes no dia corrente, ou seja, todas as entradas as quais não foram registradas saídas (Figura 2.b). Ao selecionar uma visita, o vigilante poderá registrar a saída do aluno (Figura 2.c). As informações de data e hora de saída são cadastradas automaticamente. Uma vez confirmada a saída, o registro não ficará mais visível para o vigilante.

É importante ressaltar que, com exceção da geração de relatórios (F7), todas as funcionalidades foram implementadas durante a execução do projeto. Com o retorno gradual às atividades presenciais no câmpus, espera-se que o sistema entre aos poucos em fase de implantação em cooperação com os vigilantes. Para isso, seria necessário um projeto complementar, que viesse a propor a manutenção do sistema já desenvolvido.

\section{Discussões}

A equipe do projeto foi formada por cinco discentes. Destes integrantes, dois foram selecionados como bolsistas: um desenvolvedor back-end e um full stack, cursando o $4^{\circ} \mathrm{e}$ $3^{\circ}$ período, respectivamente. Os demais integrantes participaram do projeto voluntariamente, e à época cursavam o $3^{\circ}, 6^{\circ}$ e $8^{\circ}$ períodos. Nas Seções 5.1 e 5.2, toda a equipe (incluindo docentes) discute resultados e problemas enfrentados, respectivamente. Já a Seção 5.3 traz relatos dos discentes participantes. 


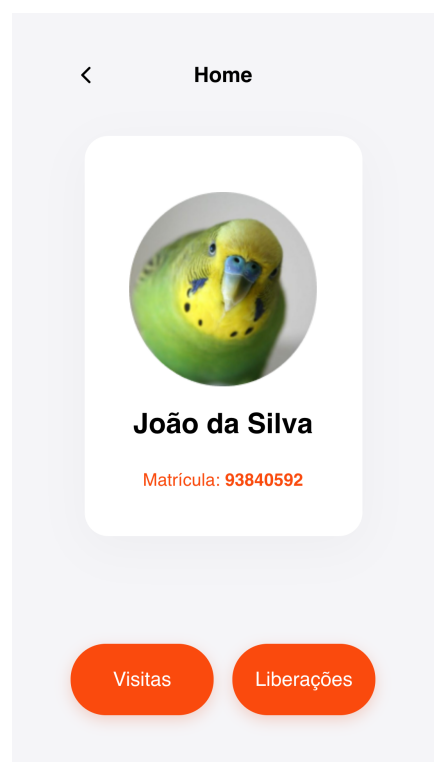

(a) Home do Vigilante

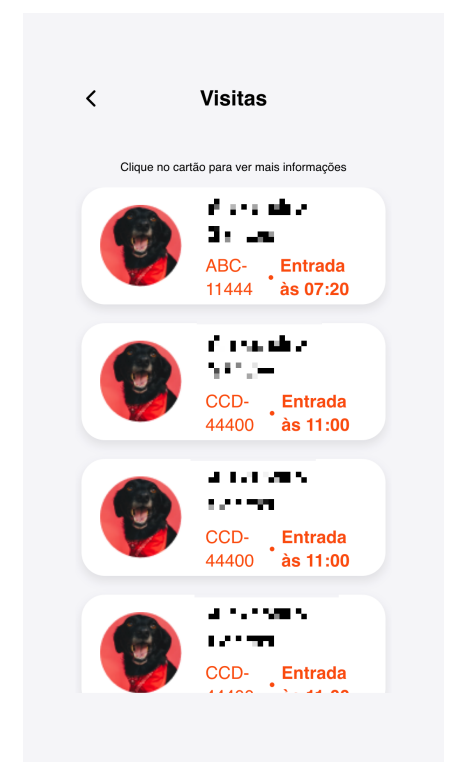

(b) Entradas registradas

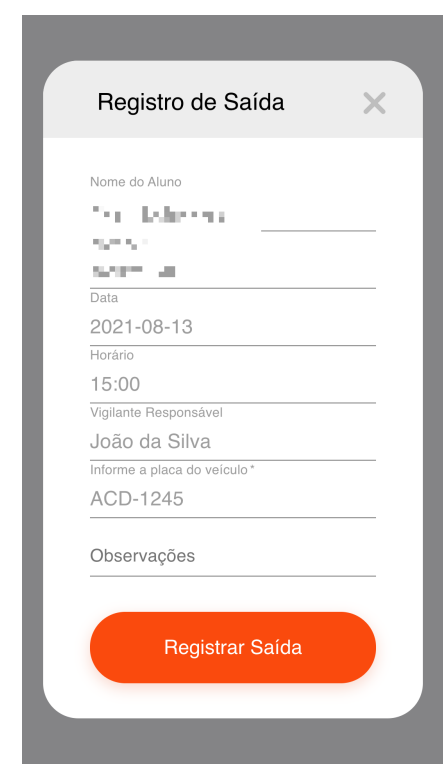

(c) Confirmação de saída

Figura 2. Telas de registro de saída (F6).

\subsection{Resultados positivos}

Participação em todo o processo. Todas as discussões sobre tecnologias, alteração de requisitos, e mudanças eventuais no processo foram discutidas em grupo, com a orientação do professor responsável. O time teve participação em todas as etapas do processo de desenvolvimento, desde a concepção até o produto final apresentado nesse relatório. No contexto das disciplinas do curso de BES, a entrega de um produto viável é extremamente limitada ao escopo de cada disciplina, podendo, em caráter excepcional, ser observado apenas nas disciplinas integralizadoras do curso.

Contato com problemas reais. No contexto de disciplinas, é comum que os alunos tragam os próprios projetos para desenvolverem alguma solução via software. Dessa forma, geralmente os alunos são os próprios clientes das aplicações que estes desenvolvem dentro do curso. No projeto "Fábrica de Software", a ocasião de um cliente externo ao time traz um contexto mais comum nas empresas de desenvolvimento, assim como traz também suas complexidades. O time por diversas vezes pôde confrontar as próprias expectativas quanto ao projeto em relação aos requisitos levantados com o cliente, podendo revisar e elucidar questões acerca desses requisitos.

Uso de conceitos avançados. Alguns discentes ainda não tinham contato com disciplinas de programação Web. Dessa forma, algumas linguagens e bibliotecas eram inéditas e houve um período de adaptação considerando uma demanda real de projeto. O ambiente colaborativo e, em várias ocasiões, o contexto de trabalho remoto contribuiu para sessões de live programming para fixação de alguns conceitos da linguagem utilizada. Outra contribuição foi o material de apoio, como tutoriais, produzidos pelo próprio time.

Motivação geral. Apesar dos problemas de adesão discutidos na seção seguinte, a equipe com cinco integrantes continuou participando do projeto, de forma voluntária, e aplicando pequenas correções ao longo das semanas após o encerramento do projeto. Os discentes 
manifestaram interesse devido a aplicação prática do projeto e a oportunidade de contribuir com o câmpus por meio do sistema proposto.

\subsection{Problemas Enfrentados}

Organização e aulas remotas. O time inicial possuía outros quatro integrantes voluntários que, ao longo da execução do projeto, se desligaram. O principal motivo foi a sobrecarga de trabalho, considerando o semestre de atividades pedagógicas não presenciais, aliado a estágios e trabalhos durante o horário comercial. Devido aos desligamentos, o docente responsável teve que constantemente remanejar as atividades em andamento, além de lidar com o desfalque de integrantes mais experientes, que poderiam auxiliar os discentes nos primeiros períodos.

Adaptação às tecnologias. Especialmente para as atividades de front-end, as tecnologias selecionadas (TypeScript e React) eram novas aos discentes. Nenhum integrante era experiente nessas tecnologias, o que gerou um atraso nas atividades iniciais para o aprendizado dessas tecnologias. Com um mês de projeto, um discente mais experiente participou da "Fábrica de Software" voluntariamente, e contribuiu substancialmente com o andamento das atividades relativas ao uso de boas práticas, melhores bibliotecas e técnicas de reuso em desenvolvimento front-end. Consequentemente, o conhecimento agregado aos demais discentes foi de grande valia para seu desempenho.

Ausência de testes. Devido ao time reduzido, o projeto contou com poucas posições dentro do time de desenvolvimento, estas descritas no início da seção. Consequentemente, não foi possível alocar um testador no time, e atividades recomendadas pela Engenharia de Software em relação a testes não foram aplicadas no projeto. O relato da experiência da "Fábrica" no IFC [Mota et al. 2014] trouxe as mesmas dificuldades nas primeiras iterações do projeto, e serviram de estudo de caso para diferentes disciplinas do curso. Assim, espera-se que os próximos projetos nesse formato incorporem novos processos de desenvolvimento e aplicações de conceitos da área de Engenharia de Software.

\subsection{Relatos dos Alunos Participantes}

Os relatos a seguir foram coletados no final do projeto. Foi solicitado aos discentes participantes que escrevessem um relato espontâneo em formato livre sobre a experiência, dificuldades e lições aprendidas durante a condução do projeto. À exceção do "Discente 3", que havia se desligado no fim do projeto por motivos pessoais, todos os discentes responderam. Os relatos abaixo são reproduzidos na íntegra assim que possível, sendo omitidas algumas informações que pudessem revelar a identidade dos participantes ou outras informações sensíveis.

\subsubsection{Discente 1 (desenvolvedor full stack, bolsista, $3^{\circ}$ período)}

Quando entrei no projeto sabia mais ou menos das dificuldades que iria encontrar, pois já estou no mercado de trabalho e tenho um pequeno conhecimento de como funciona um projeto, mas não imaginava o nível dessas dificuldades.

No início, fiquei responsável por modelar e estruturar o banco de dados que consegui fazer com até certa facilidade, pois já tinha domínio sobre a tecnologia. Porém, em determinado momento tive que trabalhar na parte de front-end e com uma linguagem 
que tinha muito pouco conhecimento. Nesse momento começaram minhas dificuldades, pois o tempo de aprendizagem era curto para fazer um curso e para produzir algo minimamente funcional. Apesar das dificuldades consegui fazer algumas entregas nesses recursos, mesmo acreditando que com mais tempo poderia ter feito algo bem melhor. [...]

Apesar das dificuldades que foram apresentar a experiência de compreender como funciona um site Web, sua criação, estruturar o banco de dados e entender todas as partes de um projeto desse tipo, foi muito proveitoso e o que eu consegui extrair no projeto será de muita importância para minha carreira.

\subsubsection{Discente 2 (desenvolvedor back-end, bolsista, $4^{\circ}$ período)}

É durante o processo prático de desenvolvimento que o aluno inexperiente percebe as dificuldades de implementação de um projeto real. Foram observadas algumas discrepâncias entre teoria e prática, seja pelo cunho didático apresentado durante o curso, seja pelo fato de as tecnologias escolhidas ainda não fazerem parte da vida de todos num dado momento. As principais dificuldades encontradas se deram pelo fato de a equipe não dispor de conhecimento técnico suficiente e esse aprendizado foi se desenvolvendo ao longo do tempo, apresentando assim, uma curva de aprendizagem relativamente acentuada.

Em decorrência dessas dificuldades, teve-se uma considerável redução na produtividade, uma vez que o tempo investido em aprendizado poderia estar sendo usado com o desenvolvimento do projeto em si. Outro obstáculo encontrado ocorreu no contexto de reunião entre os membros da equipe; como o projeto foi desenvolvido remotamente e em paralelo com as disciplinas do curso, a sincronização de ideias e a velocidade de resposta, de certa forma, foi comprometida e algumas tomadas de decisão também.

O projeto foi um "campo minado" de aprendizagens, permitindo a cada participante adquirir uma carga de conhecimento. O primeiro conhecimento foi o trabalho em equipe: compreender que o trabalho do outro depende do seu e vice-versa criou nos indivíduos um senso de responsabilidade e zelo pelas tarefas recebidas, bem como um maior comprometimento em realizar as entregas dentro do prazo estabelecido. $\mathrm{O}$ segundo relaciona-se com o conhecimento técnico: o compartilhamento e a troca de ideias entre os indivíduos foi fundamental para a disseminação do que foi aprendido: lidar com banco de dados, versionamento de código, deploy, particularidades da linguagem, leitura de documentação, padronização, dentre outros, foram sem dúvida, enriquecedores e contribuíram para a formação profissional.

\subsubsection{Discente 4 (desenvolvedor front-end, voluntário, $3^{\circ}$ período)}

Quando o escopo de um projeto é grande, a equipe é dividida por papéis nos quais a atuação dos desenvolvedores são diferentes, como front-end, back-end, UI/UX, etc. Porém, todos são iniciantes lidando com projetos sem uma figura experiente para apontar as maneiras corretas de desenvolver. Essa situação acaba sendo uma faca de dois gumes para o projeto, já que uma das principais ideias é justamente aprender mais e compartilhar o que você sabe para o outro. Porém, é ao mesmo tempo falível já que não há um norte para o correto naquela situação ou outra, o que pode atrasar o projeto ainda mais. 
De fato, receber toda essa responsabilidade é bem excitante e nos traz desafios para buscarmos não só nossos limites, mas também ultrapassá-los e nos tornar cada vez melhores. Ingressar em um projeto novo traz tanto ânimo que focamos nisso temporariamente e esquecemos do resto, e esse resto não é qualquer coisa: trabalho, faculdade, vida pessoal e outros contratempos que aparecem são só algumas das coisas que tivemos que lidar no dia a dia e, querendo ou não, refletem no nosso desempenho no projeto. Num mar de responsabilidades, um projeto pequeno e sem muita supervisão não requer muita dedicação de tempo e é aí que mora o perigo, já que é algo que é muito importante e envolve outras pessoas, recursos, comprometimento e tempo.

Quais são os elementos que nos mantém presos à algo? O que nos faz perder o interesse e recuperar? Puxar a responsabilidade e ir atrás para entregar o melhor resultado? Não dá pra saber, ou até dá, mas fazer acontecer é algo diferente e acredito que só uma pessoa conseguiu fazer isso e não é à toa que ela é a mais experiente do projeto [o Product Owner]. O que podemos aprender não com só essa pessoa determinada, paciente e proativa, mas com todo o projeto para que sejamos melhores? Talvez se todos tirassem essas dúvidas da cabeça e dessem seu melhor seria a melhor alternativa, o que realmente aconteceu em alguns momentos onde uns brilharam e outros tentaram, e no final de tudo, fizemos acontecer. Talvez não excepcionalmente como gostaríamos, mas especialmente o suficiente para poder olhar e falar, "eu fiz isso" e não parar por aí e surgir pensamentos, como "eu posso ainda mais, eu vou conseguir".

\subsubsection{Discente 5 (Designer e Scrum Master, voluntário, $8^{\circ}$ período)}

Durante o andamento de projeto fiquei na posição de Scrum Master. Achei muito interessante, pois não tinha tipo essa experiência ainda, seja de forma acadêmica ou profissional. Considero uma posição muito importante, pois é a pessoa responsável pela organização das reuniões entre outras atividades, como auxiliar os demais integrantes da equipe com materiais ou outras coisas que fossem necessárias para que os mesmos executassem suas atividades. Apesar disso, não fui muito solicitado nessa ultima questão, acredito que pelo motivo de a equipe ser autodidata e já bem engajados uns com os outros.

Além disso desempenhei o papel de designer durante parte do projeto. Como o padrão das interfaces já havia sido definido, considerei um trabalho simples. A parte criativa, que considero que seja o mais difícil deste cargo já havia sido realizada, então somente utilizei esses conceitos para construir as demais interfaces necessárias.

\section{Conclusões}

Ao fim da primeira experiência do projeto "Fábrica de Software", foi possível proporcionar uma experiência completa de desenvolvimento de software junto aos discentes participantes. O projeto contou com a participação de discentes tanto dos períodos iniciais $\left(3^{\circ}\right.$ e $\left.4^{\circ}\right)$ quanto formandos, além de discentes que já possuíam experiência profissional. Por se tratar de um projeto piloto, algumas dificuldades foram encontradas, tanto devido ao formato do projeto quanto às atividades paralelas dos discentes (e.g., trabalho, disciplinas remotas, etc.). Como maior resultado, foi desenvolvido um sistema que atende as necessidades de um setor do câmpus, a ser em breve implantado e disponibilizado junto aos seus usuários finais, a saber: servidores, docentes e vigilantes. 
Assim como outros resultados de trabalhos relacionados, o incentivo do trabalho em equipe e autoregulado proporcionou um ambiente de ensino mais complexo, no qual os discentes foram responsáveis por um projeto com cliente e demandas reais [Borges et al. 2012]. Como todo trabalho inicial, há lições a serem aprendidas, em especial em um ambiente de desenvolvimento diverso e totalmente remoto. Algumas atividades importantes da Engenharia de Software, assim como a validação do projeto junto aos interessados acabaram não sendo realizadas, devido tanto ao tamanho limitado da equipe, quanto às restrições impostas pela pandemia COVID-19. Além disso, uma vez que a "Fábrica" foi executada como projeto de Ensino, em contraponto a estágios ou disciplinas que possuem avaliações, não havia consequências diretas do não cumprimento das atividades, o que estimulou os constantes atrasos. Nesse sentido, os trabalhos relacionados não previram esses cenários e não trouxeram essa discussão.

No entanto, a equipe se manteve motivada principalmente porque o resultado era observável e cada atualização era uma conquista conjunta. O projeto agregou a aprendizagem de tecnologias novas aos discentes, o que proporcionou amplo material de apoio que servirá para as iterações de projetos semelhantes. Atualmente, os docentes do curso de BES estudam a adaptação do projeto "Fábrica" nos requisitos para inclusão de disciplinas de extensão, com o objetivo de atender demandas da sociedade civil da cidade. $\mathrm{O}$ formato da "Fábrica" será crucial para o desenvolvimento desses novos projetos e de tantas outras demandas internas da Instituição de Ensino, de modo a aliar atividades pedagógicas e práticas num desenvolvimento de software com qualidade.

\section{Referências}

Borges, K. S., de Carvalho, T. P., and de Moraes, M. A. C. (2012). Programa de extensão "Fábrica de Software Acadêmica": contribuindo para a formação profissional na área da informática. In XX Workshop sobre Educação em Computação, pages 1-9.

Chanin, R., Melegati, J., Sales, A., Detoni, M., Wang, X., and Prikladnicki, R. (2019). Incorporating real projects into a software engineering undergraduate curriculum. In 2019 IEEE/ACM 41 st International Conference on Software Engineering: Companion Proceedings (ICSE-Companion), pages 250-251.

Conselho Nacional de Educação (2020). Resolução nº 5, de 16 de novembro de 2016.

Dutra, A. C. S., Majdenbaum, A., Trindade, C. A. W., Callegari, D. A., and Yamaguti, M. H. (2017). Percepção da contribuição da AGES para o aprendizado em engenharia de software. In Anais da $1^{a}$ Escola Regional Engenharia de Software (ERES 2017), pages $105-110$.

Martin, R. C. (2009). Clean code: a handbook of agile software craftsmanship. Pearson Education.

Mota, C. J., da Silva, E., Braz, F. J., Riegel, I. M., Mota, J. S., Mendes, M. A. L., and de Oliveira, P. C. F. (2014). A experiência do ambiente da Fábrica de Software nas atividades de ensino do curso de Sistemas de Informação do IFC - Campus Araquari. In XXII Workshop sobre Educação em Computação, pages 1545-1554.

Schwaber, K. and Sutherland, J. (2017). The Definitive Guide to Scrum: The Rules of the Game. 